\title{
Evaluation of Agile Suppliers Using Fuzzy MCDM Approach
}

\author{
Mehtap Dursun ${ }^{1, a}$ \\ ${ }^{1}$ Galatasaray University, Industrial Engineering Department, 34349, Ortakoy, Istanbul, Turkey
}

\begin{abstract}
In today's competitive environment, supply chain need to be of high speed and flexibility, i.e., agile. Agility has been proposed as a response to the high levels of complexity and uncertainty in modern markets. It is a business-wide capability that embraces organizational structures, information systems and logistics processes. This study employs the hierarchical fuzzy MCDM algorithm proposed by Karsak and Ahiska for the evaluation of agile suppliers. This algorithm is based on the proximity to the ideal solution concept and it can address the problems containing both crisp and fuzzy data. The application of the decision making method is illustrated through a case study conducted in a privet hospital and the results are analysed.
\end{abstract}

\section{Introduction}

Supply chain is composed of a complex sequence of processing stages, ranging from raw materials supplies, parts manufacturing, components and end-products assembling, to the delivery of end products. In the context of supply chain management, supplier selection decision is considered as one of the key issues faced by operations and purchasing managers to remain competitive.

Supplier selection and management can be applied to a variety of suppliers throughout a product's life cycle from initial raw material acquisition to end-of-life service providers. Thus, the breadth and diversity of suppliers make the process even more cumbersome. Supplier selection process has different phases such as problem definition, decision criteria formulation, pre-qualification of potential suppliers, and making a final choice. The quality of the final choice largely depends on the quality of all the steps involved in the selection process.

Recently, industries face significant changes especially in marketing competition, technological innovation, and customer demands. Situations and possibilities are varied and organizations are responsible for adapting themselves to this various cases. Moreover, the scarce sources are considered as an important restriction faced by the companies. Agility is essential to deal with these problems. The term agility can be defined as an ability to give quick responses to changes and unpredictable situations. It is considered as the bearer competitive advantage in today's business environment. Companies have to be aligned with suppliers, customers, and competitors within the supply chain. Also, they should work together to achieve a level of agility.

Supply chain agility is implemented in which the ordered innovative goods with small volumes of high margin in addition to short product life cycle through a complex global supply chain network. It is applied an equilibrium solution which copes with the complexity in a limited coordination and cooperation through the links in the network. The agility of supply chain might be measured as how well supply chain elements, suppliers, customers and competitors are coordinated and collaborated in the network enhance four pivotal objectives of agile manufacturing which are customer enrichment ahead of competitors, achieving mass customization at the cost of mass production, mastering change and uncertainty through routinely adaptable structures, and leveraging the impact of people across enterprises through information technology [1].

This study aims to develop multi-criteria decision making approach for evaluating agile suppliers. Supplier evaluation process requires the consideration of multiple conflicting criteria, yielding in a multi-level hierarchical structure, incorporating vagueness and imprecision with the involvement of a group of experts. Fuzzy set theory is one of the effective tools to deal with uncertainty and vagueness in criteria values. The objective of this study is to propose a hierarchical fuzzy multi-criteria group decision making methodology for agile supplier evaluation.

In the literature, there are a few papers that evaluate agile suppliers. $\mathrm{Wu}$ et al. [2] proposed a two-stage approach, based on the application of analytic network process (ANP) and mixed integer multi-objective programming model, to solve the problem of partner selection in agile supply chains. Wu and Barnes [3] presented a four phase dynamic feedback model for supply partner selection in agile supply chains. Alminardi et al. [4] combined SWARA and VIKOR for supplier selection in an agile environment. Abdollahi et al. [5] integrated analytic network process (ANP) and data

\footnotetext{
$\overline{{ }^{a} \text { Corresponding author: mdursun } @ g s u . e d u . t r}$
} 
envelopment analysis (DEA), and DEMATEL method for evaluating suppliers considering lean and agile criteria. Lee et al. [6] employed fuzzy AHP and fuzzy TOPSIS to select suppliers. Beikkhakhian et al. [7] identified the criteria to evaluate agile suppliers and then they used fuzzy TOPSIS to rank alternative suppliers.

The rest of the paper is organized as follows. Section 2 analyzed the fuzzy decision making methodology employed in this study for the evaluation of agile suppliers. Section 3 presents the application of the proposed model. Finally, conclusions are provided in Section 4

\section{Hierarchical fuzzy MCDM approach}

Real-world decision problems such as the supplier selection often involve the consideration of numerous performance attributes. When a large number of performance attributes are to be considered in the evaluation process, it may be preferred to structure them in a multi-level hierarchy in order to conduct a more effective analysis. In this study, the hierarchical distancebased fuzzy MCDM algorithm introduced by Karsak and Ahiska [8] is employed for evaluating agile suppliers. This MCDM algorithm is based on the proximity to the ideal solution concept and which can address the problems containing both crisp and fuzzy data. The origins of the proposed decision making procedure are found in the multi-criteria decision tool named TOPSIS [9].

The proposed fuzzy MCDM approach can be described as follows:

Step 1. Construct the decision matrix that denotes the fuzzy assessments corresponding to qualitative subcriteria and the crisp values corresponding to quantitative sub-criteria for the considered alternatives.

Step 2. Normalize the crisp data to obtain unit-free and comparable sub-criteria values. The normalized values for crisp data regarding benefit-related as well as cost-related quantitative sub-criteria are calculated via a linear scale transformation as

$$
y_{i j k}^{\prime}= \begin{cases}\frac{y_{i j k}-y_{j k}^{-}}{y_{j k}^{*}-y_{j k}^{-}}, & k \in C B_{j} ; i=1,2, \ldots, m ; j=1,2, \ldots, n \\ \frac{y_{j k}^{*}-y_{i j k}}{y_{j k}^{*}-y_{j k}^{-}}, & k \in C C_{j} ; i=1,2, \ldots, m ; j=1,2, \ldots, n\end{cases}
$$

where $y_{i j k}^{\prime}$ denotes the normalized value of $y_{i j k}$, which is the crisp value assigned to alternative $i$ with respect to the sub-criterion $k$ of criterion $j, m$ is the number of alternatives, $n$ is the number of criteria, $C B_{j}$ is the set of benefit-related crisp sub-criteria of criterion $j$ and $C C_{j}$ is the set of cost-related crisp sub-criteria of criterion $j$, $y_{j k}^{*}=\max _{i} y_{i j k}$ and $y_{j k}^{-}=\min _{i} y_{i j k}$. The normalized values for crisp data can be represented as $\tilde{y}_{i j k}=\left(y_{a i j k}^{\prime}, y_{b i j k}^{\prime}, y_{c i j k}^{\prime}\right)$ in triangular fuzzy number format, where $y_{a i j k}^{\prime}=y_{b i j k}^{\prime}=y_{c i j k}^{\prime}=y_{i j k}^{\prime}$.
Step 3. Aggregate the performance ratings of alternatives at the sub-criteria level to criteria level as follows:

$$
\tilde{x}_{i j}=\left(x_{a i j}, x_{b i j}, x_{c i j}\right)=\frac{\sum_{k} \widetilde{w}_{j k}^{1} \otimes \tilde{y}_{i j k}}{\sum_{k} \widetilde{w}_{j k}^{1}}, \forall i, j
$$

where $\tilde{x}_{i j}$ represents the aggregate performance rating of alternative $i$ with respect to criterion $j, \widetilde{w}_{j k}^{1}$ indicates the average importance weight assigned to sub-criterion $k$ of criterion $j$, and $\otimes$ is the fuzzy multiplication operator.

Step 4. Normalize the aggregate performance ratings at criteria level using a linear normalization procedure, which results in the best value to be equal to 1 and the worst one to be equal to 0 , as follows:

$$
\widetilde{r}_{i j}=\left(r_{a i j}, r_{b i j}, r_{c i j}\right)=\left(\frac{x_{a i j}-x_{a j}^{-}}{x_{c j}^{*}-x_{a j}^{-}}, \frac{x_{b i j}-x_{a j}^{-}}{x_{c j}^{*}-x_{a j}^{-}}, \frac{x_{c i j}-x_{a j}^{-}}{x_{c j}^{*}-x_{a j}^{-}}\right), \forall i, j(3)
$$

where $x_{c j}^{*}=\max _{i} x_{c i j}, x_{a j}^{-}=\min _{i} x_{a i j}$, and $\tilde{r}_{i j}$ denotes the normalized aggregate performance rating of alternative $i$ with respect to criterion $j$.

Step 5. Define the ideal solution $A^{*}=\left(r_{1}^{*}, r_{2}^{*}, \ldots, r_{n}^{*}\right)$ and the anti-ideal solution $A^{-}=\left(r_{1}^{-}, r_{2}^{-}, \ldots, r_{n}^{-}\right), \quad$ where $\quad r_{j}^{*}=(1,1,1) \quad$ and $r_{j}^{-}=(0,0,0)$ for $j=1,2, \ldots, n$.

Step 6. Calculate the weighted distances from ideal solution and anti-ideal solution $\left(D_{i}^{*}\right.$ and $D_{i}^{-}$, respectively) for each alternative as

$$
\begin{aligned}
& D_{i}^{*}=\sum_{j} 1 / 2\left\{\max \left(w_{a j}^{1}\left|r_{a i j}-1,, w_{c j}^{1}\right| r_{c i j}-1 \mid\right)+w_{b j}^{1}\left|r_{b i j}-1\right|\right\}, i=1,2, \ldots, m(4) \\
& D_{i}^{-}=\sum_{j} 1 / 2\left\{\max \left(w_{a j}^{1}\left|r_{a i j}-0\right|, w_{c j}^{1}\left|r_{c i j}-0\right|\right)+w_{b j}^{1}\left|r_{b i j}-0\right|\right\}, i=1,2, \ldots, m(5)
\end{aligned}
$$

Step 7. Calculate the proximity of the alternatives to the ideal solution, $P_{i}^{*}$, by considering the distances from ideal and anti-ideal solutions as

$$
P_{i}^{*}=D_{i}^{-} /\left(D_{i}^{*}+D_{i}^{-}\right), i=1,2, \ldots, m .
$$

Step 8. Rank the alternatives according to $P_{i}^{*}$ values in descending order. Identify the alternative with the highest $P_{i}^{*}$ as the best alternative.

\section{Case study}

In order to illustrate the application of the proposed decision making method, a case study conducted in a private hospital on the Asian side of Istanbul is presented. Benefiting from the literature, management capability, manufacturing capability, collaboration capability, and 
agility, and their related sub-criteria are identified as the selection attributes as in Table 1.

Table 1. Criteria and related sub-criteria.

\begin{tabular}{|c|c|c|}
\hline Main criteria & & Sub-criteria \\
\hline $\begin{array}{l}\text { Management } \\
\left(\mathrm{C}_{1}\right)\end{array}$ & capability & $\begin{array}{l}\text { Management and Organization } \\
\left(\mathrm{C}_{11}\right) \\
\text { Financial position }\left(\mathrm{C}_{12}\right) \\
\text { Customer relation }\left(\mathrm{C}_{13}\right) \\
\text { Training aids }\left(\mathrm{C}_{14}\right) \\
\text { Reputation }\left(\mathrm{C}_{15}\right)\end{array}$ \\
\hline $\begin{array}{l}\text { Manufacturing } \\
\left(\mathrm{C}_{2}\right)\end{array}$ & capability & $\begin{array}{l}\text { Production capacity }\left(\mathrm{C}_{21}\right) \\
\text { Product diversity }\left(\mathrm{C}_{22}\right) \\
\text { R\&D }\left(\mathrm{C}_{23}\right) \\
\text { Quality }\left(\mathrm{C}_{24}\right)\end{array}$ \\
\hline $\begin{array}{l}\text { Collaboration } \\
\left(\mathrm{C}_{3}\right)\end{array}$ & capability & $\begin{array}{l}\text { Delivery reliability }\left(\mathrm{C}_{31}\right) \\
\text { Warranties and claim policies } \\
\left(\mathrm{C}_{32}\right)\end{array}$ \\
\hline Agility $\left(\mathrm{C}_{4}\right)$ & & $\begin{array}{l}\text { Delivery speed }\left(\mathrm{C}_{41}\right) \\
\text { Delivery flexibility }\left(\mathrm{C}_{42}\right) \\
\text { Agile customer responsiveness } \\
\left(\mathrm{C}_{43}\right) \\
\text { Collaboration with partners }\left(\mathrm{C}_{44}\right) \\
\text { Make flexibility }\left(\mathrm{C}_{45}\right) \\
\text { Source flexibility }\left(\mathrm{C}_{46}\right)\end{array}$ \\
\hline
\end{tabular}

The expert used the linguistic variables given in Figure 1 to evaluate the importance of the criteria and sub-criteria, and also the ratings of alternatives with respect to various subjective criteria and sub-criteria. There are 4 suppliers who are in contact with the hospital.

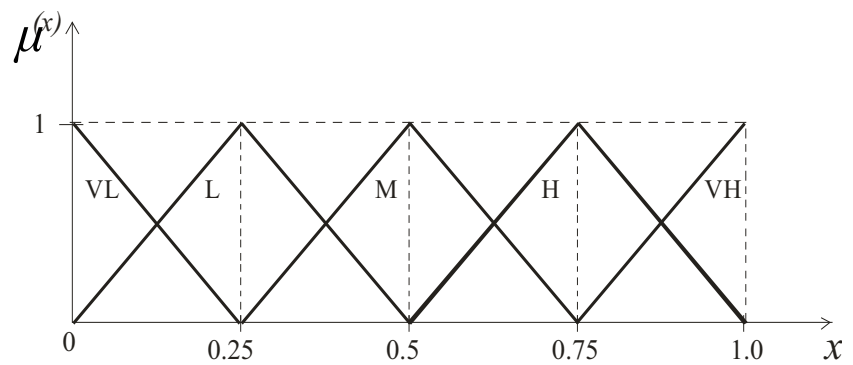

Figure 1. A linguistic term set where $\mathrm{VL}=(0,0,0.25), \mathrm{L}=(0$, $0.25,0.5), \mathrm{M}=(0.25,0.5,0.75), \mathrm{H}=(0.5,0.75,1), \mathrm{VH}=(0.75$, $1,1)$

The evaluations are represented in Tables 2, 3, and 4 .

Table 2. Importance weights of criteria.

\begin{tabular}{cc}
\hline Criteria & Importance weight \\
\hline $\mathrm{C}_{1}$ & $\mathrm{H}$ \\
$\mathrm{C}_{2}$ & $\mathrm{H}$ \\
$\mathrm{C}_{3}$ & $\mathrm{M}$ \\
$\mathrm{C}_{4}$ & $\mathrm{VH}$ \\
\hline
\end{tabular}

Table 3. Importance weights of sub-criteria.

\begin{tabular}{cc}
\hline Sub-Criteria & Importance weight \\
\hline $\mathrm{C}_{11}$ & $\mathrm{VH}$ \\
$\mathrm{C}_{12}$ & $\mathrm{H}$ \\
$\mathrm{C}_{13}$ & $\mathrm{VH}$ \\
$\mathrm{C}_{14}$ & $\mathrm{M}$ \\
$\mathrm{C}_{15}$ & $\mathrm{H}$ \\
$\mathrm{C}_{21}$ & $\mathrm{H}$ \\
$\mathrm{C}_{22}$ & $\mathrm{VH}$ \\
$\mathrm{C}_{23}$ & $\mathrm{H}$ \\
$\mathrm{C}_{24}$ & $\mathrm{VH}$ \\
$\mathrm{C}_{31}$ & $\mathrm{H}$ \\
$\mathrm{C}_{32}$ & $\mathrm{H}$ \\
$\mathrm{C}_{41}$ & $\mathrm{H}$ \\
$\mathrm{C}_{42}$ & $\mathrm{H}$ \\
$\mathrm{C}_{43}$ & $\mathrm{VH}$ \\
$\mathrm{C}_{44}$ & $\mathrm{H}$ \\
$\mathrm{C}_{45}$ & $\mathrm{VH}$ \\
$\mathrm{C}_{46}$ & $\mathrm{VH}$ \\
\hline
\end{tabular}

Table 4. Data related to agile supplier evaluation problem.

\begin{tabular}{ccccc}
\hline Sub-Criteria & $S_{1}$ & $S_{2}$ & $S_{3}$ & $S_{4}$ \\
\hline $\mathrm{C}_{11}$ & $\mathrm{M}$ & $\mathrm{M}$ & $\mathrm{M}$ & $\mathrm{H}$ \\
$\mathrm{C}_{12}$ & $\mathrm{VL}$ & $\mathrm{L}$ & $\mathrm{L}$ & $\mathrm{VH}$ \\
$\mathrm{C}_{13}$ & $\mathrm{VH}$ & $\mathrm{VH}$ & $\mathrm{VH}$ & $\mathrm{VH}$ \\
$\mathrm{C}_{14}$ & $\mathrm{M}$ & $\mathrm{H}$ & $\mathrm{H}$ & $\mathrm{H}$ \\
$\mathrm{C}_{15}$ & $\mathrm{VL}$ & $\mathrm{VL}$ & $\mathrm{VL}$ & $\mathrm{VL}$ \\
$\mathrm{C}_{21}$ & $\mathrm{VH}$ & $\mathrm{H}$ & $\mathrm{H}$ & $\mathrm{L}$ \\
$\mathrm{C}_{22}$ & $\mathrm{VH}$ & $\mathrm{H}$ & $\mathrm{H}$ & $\mathrm{M}$ \\
$\mathrm{C}_{23}$ & $\mathrm{M}$ & $\mathrm{M}$ & $\mathrm{L}$ & $\mathrm{H}$ \\
$\mathrm{C}_{24}$ & $\mathrm{~L}$ & $\mathrm{~L}$ & $\mathrm{M}$ & $\mathrm{M}$ \\
$\mathrm{C}_{31}$ & $\mathrm{VH}$ & $\mathrm{H}$ & $\mathrm{H}$ & $\mathrm{M}$ \\
$\mathrm{C}_{32}$ & $\mathrm{VH}$ & $\mathrm{H}$ & $\mathrm{H}$ & $\mathrm{M}$ \\
$\mathrm{C}_{41}$ & $\mathrm{VH}$ & $\mathrm{H}$ & $\mathrm{H}$ & $\mathrm{L}$ \\
$\mathrm{C}_{42}$ & $\mathrm{H}$ & $\mathrm{H}$ & $\mathrm{H}$ & $\mathrm{VH}$ \\
$\mathrm{C}_{43}$ & $\mathrm{H}$ & $\mathrm{H}$ & $\mathrm{H}$ & $\mathrm{H}$ \\
$\mathrm{C}_{44}$ & $\mathrm{M}$ & $\mathrm{M}$ & $\mathrm{H}$ & $\mathrm{H}$ \\
$\mathrm{C}_{45}$ & $\mathrm{H}$ & $\mathrm{VH}$ & $\mathrm{H}$ & $\mathrm{VH}$ \\
$\mathrm{C}_{46}$ & $\mathrm{H}$ & $\mathrm{M}$ & $\mathrm{M}$ & $\mathrm{H}$ \\
\hline
\end{tabular}

Sub-criteria values are aggregated to criteria level using equation (2), and are represented in Table 5.

Table 5. Data related to agile supplier evaluation problem.

\begin{tabular}{ccccc}
\hline Criteria & $\mathrm{S}_{1}$ & $\mathrm{~S}_{2}$ & $\mathrm{~S}_{3}$ & $\mathrm{~S}_{4}$ \\
\hline $\mathrm{C}_{1}$ & $(0.30,0.44,0.59)$ & $(0.32,0.52,0.68)$ & $(0.32,0.52,0.68)$ & $(0.52,0.72,0.84)$ \\
$\mathrm{C}_{2}$ & $(0.45,0.72,0.84)$ & $(0.32,0.58,0.84)$ & $(0.34,0.59,0.84)$ & $(0.25,0.50,0.75)$ \\
$\mathrm{C}_{3}$ & $(0.75,1,1)$ & $(0.50,0.75,1)$ & $(0.50,0.75,1)$ & $(0.25,0.50,0.75)$ \\
$\mathrm{C}_{4}$ & $(0.50,0.75,0.96)$ & $(0.47,0.71,0.92)$ & $(0.45,0.70,0.96)$ & $(0.52,0.77,0.92)$ \\
\hline
\end{tabular}


The normalized values of these aggregate performance ratings are computed using equation (3). The ideal and the anti-ideal solutions are defined as $A^{*}=((1,1,1), \quad(1,1,1), \quad(1,1,1), \quad(1,1,1)) \quad$ and $A^{-}=((0,0,0)$, $(0,0,0),(0,0,0),(0,0,0))$, respectively. The weighted distances from ideal and anti-ideal solutions and the proximity of the alternatives to the ideal solution are calculated employing Eqs. (4)-(6). The results are shown in Table 6.

Table 6. Data related to agile supplier evaluation problem.

\begin{tabular}{ccccc}
\hline $\mathrm{S}_{i}$ & $D_{i}^{*}$ & $D_{i}^{*}$ & $P_{i}^{*}$ & Ranking \\
\hline $\mathrm{S}_{1}$ & 1.354 & 2.586 & 0.656 & 1 \\
$\mathrm{~S}_{2}$ & 1.624 & 2.119 & 0.567 & 3 \\
$\mathrm{~S}_{3}$ & 1.626 & 2.014 & 0.553 & 4 \\
$\mathrm{~S}_{4}$ & 1.508 & 2.470 & 0.621 & 2 \\
\hline
\end{tabular}

The rank order of the suppliers is $\mathrm{S}_{1} \succ \mathrm{S}_{4} \succ \mathrm{S}_{2} \succ \mathrm{S}_{3}$. According to the results of the analysis, supplier 1 is determined as the most suitable supplier, which is followed by supplier 4 . Supplier 3 is ranked at the bottom due to inadequate financial position, reputation, and R\&D.

\section{Conclusions}

In this study, the hierarchical fuzzy MCDM algorithm proposed by Karsak and Ahiska [8] has been employed for the evaluation of agile suppliers. In classical MCDM methods, the ratings and the weights of the criteria are assumed to be known precisely. In general, crisp data are inadequate to model real-life situations. Besides having the capability of considering numerous attributes that are structured in a multi-level hierarchy, the proposed decision framework enables the decision-makers to use linguistic terms.

Considering the fact that an alternative with the shortest distance from the ideal alternative may not have the farthest distance from the anti-ideal, Karsak and Ahiska's decision algorithm takes into account the weighted distances from both the ideal and anti-ideal simultaneously. Furthermore, Karsak and Ahiska's approach does not require the use of fuzzy number ranking methods, which may yield different results according to the ranking method selected for application purposes.

Further researches might focus on the extensions of the proposed methodology by employing both subjective and objective weight assessments of the criteria and related sub-criteria.

\section{Acknowledgement}

This work has been financially supported by Galatasaray University Research Fund 16.402.010.

\section{References}

1. Z. Nagy, T. Hartványi, Agility in supply chains, Acta Technica Jaurinensis Series Logistica, 1(2), 315-323, (2008).

2. C. Wu, D. Barnes, D. Rosenberg et al., An analytic network process-mixed integer multi-objective programming model for partner selection in agile supply chains, Production Planning \& Control, 20(3), 254-275, (2009).

3. C. Wu, D. Barnes, A dynamic feedback model for partner selection in agile supply chains, International Journal of Operations \& Production Management, 32(1-2), 79-103, (2012).

4. M. Alimardani, H.Z. Sarfaraz, M.H. Aghdaie, et al., A novel hybrid SWARA and VIKOR methodology for supplier selection in an agile environment, Technological and Economic Development of Economy, 19(3), 553-548, (2013).

5. M. Abdollahi, M. Arvan, J. Razmi, An integrated approach for supplier portfolio selection: Lean or agile?, Expert Systems with Applications, 42(1), 679-690, (2015).

6. J. Lee, H. Cho, Y.S. Kim, Assessing business impacts of agility criterion and order allocation strategy in multi-criteria supplier selection, Expert Systems with Applications, 1136-1148, (2015).

7. Y. Beikkhakhian, M. Javanmardi, M. Karbasian, et al., The application of ISM model in evaluating agile suppliers selection criteria and ranking suppliers using fuzzy TOPSIS-AHP methods, Expert Systems with Applications, 42(15-16), (2015).

8. E.E. Karsak, S.S. Ahiska, Fuzzy multi-criteria decision making approach for transport projects evaluation in Istanbul, Lecture Notes in Computer Science, 3483, 301 - 311, (2005).

9. C.L. Hwang, K. Yoon, Multiple attribute decision making: methods and applications, Heidelberg, (1981). 